\title{
Impact of Implementation of Rotem on Allogenic Blood Transfusions in Trauma Patients Following ICU Admission - before and after Study -
}

\author{
Michaela Wilhelmi $^{{ }^{1}}$, Mathias Wilhelmi ${ }^{2}$, Christian Krettek ${ }^{1}$, Felix Flöricke ${ }^{3}$, \\ Frank Hildebrand $^{4}$, Hagen Andruszkow ${ }^{4}$, Alexander A. Hanke ${ }^{3}$ \\ ${ }^{1}$ Trauma Department, Hannover Medical School, Hannover, Germany \\ ${ }^{2}$ Department of Cardiothoracic-, Transplantation and Vascular-Surgery, Division of Vascular and \\ Endovascular Surgery, Hannover Medical School, Carl-Neuberg-Str.1, 30625 Hannover, Germany \\ ${ }^{3}$ Department of Anaesthesiology and Intensive Care Medicine, Hannover Medical School, Carl-Neuberg-Str.1, \\ 30625 Hannover, Germany \\ ${ }^{4}$ Department of Trauma and Reconstructive Surgery, University Hospital Aachen, Pauwelsstr. 30, 52074 \\ Aachen, Germany
}

*Corresponding Author: Michaela Wilhelmi, Trauma Department, Hannover Medical School, Hannover, Germany,Email: Wilhelmi.Michaela@mh-hannover.de

\begin{abstract}
Introduction: Intensive care treatment of multiple traumatized patients often results in transfusion of blood and coagulation products, which in many cases are administered solely based on conventional blood analyses. Beside a high socioeconomic burden, transfusion management is associated with the risk of additional in-hospital complications like acute respiratory distress syndrome (ARDS) and multiple organ dysfunction syndrome (MODS) making a specific and target-aimed coagulation-management more pronounced. In order to evaluate the impact of a rotational-thromboelastometric (ROTEM®) coagulation management towards the quantity of transfused blood products and outcome, we performed a prospective study including adult multiple traumatized patients (Injury Severity Score (ISS) $\geq 16$ points) in a single level I trauma center.
\end{abstract}

Material and Methods: Hemostatic therapy of multiple traumatized patients $(n=62)$ was performed prospectively by using the ROTEM®-method and compared to a retrospectively analyzed cohort $(n=109)$, who was treated according to conventional blood-analyses. Patients were characterized by age, body mass index (BMI), trauma injury severity scores (ISS), and Glascow Coma Scale (GCS). Evaluated parameters included the quantity of transfused blood-and coagulation-products (packed red blood cells (pRBCs), platelets (PLTS), fresh-frozen plasma (FFPs), fibrinogen (Fb), PPSB, antithrombin-III (AT-III), and tranexamic acid (TXA). In-hospital outcome was determined by presence of ARDS and multiple organ dysfunction syndrome (MODS). Logistic regression analysis was performed to identify independent influencing factors towards mortality.

Results: No differences regarding demographic factors and injury severity were found between the study groups ( $p>0.05)$. However, during ICU-treatment the ROTEM®-group received less pRBCs FFPs, and PLTs ( $p<0.001)$ compared to the retrospective study cohort, whereas the administration of TXA and Fb was increased ( $p<0.001)$. At least, PPSB and AT-III did not differ between groups $(p>0.05)$. Referring to inhospital outcome, patients in the ROTEM® group developed less frequently ARDS $(p<0.001)$, while both groups developed multi organ dysfunction syndrome (MODS) comparably. The logistic regression analysis revealed that administration of TXA was associated with improved survival.

Conclusion: Our current data clearly indicate, that in contrast to treatment based on conventional blood analyses alone, ROTEM®-based coagulation management may help to reduce blood transfusion and incidence of ARDS. Furthermore, the specific administration of TXA when using ROTEM® seems to impact the in-hospital survival of multiple traumatized patients considerably.

Keywords: Trauma, rotation thromboelastometry, coagulation, coagulopathy 


\section{INTRODUCTION}

Trauma is known as the leading cause of death in young patients aged 5 to 44 years [1]. Despite several improvements in the treatment of traumatized patients during the last decades, uncontrolled hemorrhage remains the primary reason for mortality within the first 48 hours after hospital admission [2]. In this respect, $40 \%$ of all traumatized patients have been shown to develop a so-called trauma induced coagulopathy (TIC) resulting in uncontrollable non-surgical bleeding [3, 4]. Early traumainduced coagulopathy is associated with the requirement of massive blood transfusion, prolonged intensive care treatment, and a fourfold increase of mortality [4]. Furthermore, it has been demonstrated that TIC and its associated requirement of transfusion increased the incidence of the systemic inflammatory response syndrome (SIRS), sepsis and multiple organ dysfunction syndrome (MODS) [5, 6]. Consequently, it seems to be vital to detect and treat TIC in traumatized patients at an early stage to avoid hemorrhage, hemorrhagic shock, and to reduce the administration of blood products decreasing in-hospital complications and mortality. Clinical observations and scientific findings still recommend a hemostatic management during the early in-hospital resuscitation including the administration of a large number of blood products [7, 8]. Several studies have shown a reduced mortality when pRBCs and FFPs were administered in a 1:1 ratio $[9,10]$. However, due to its significant influence towards complications, e.g. transfusion related acute lung injury (TRALI), transfusion associated circulatory overload (TACO) [11-13], and increase of nosocomial infections $[14,15]$ the administration of FFPs is still discussed controversially. In this context, a point-of-care diagnostic like viscoelastic analyses of clot formation might reduce the transfusion of allogeneic blood products and thus, may influence the clinical outcome considerably. Over the last years, viscoelastic methods such as thromboelastometry and thrombelastography (ROTEM $®$ / TEG®) were increasingly used for early detection of TIC and consequently hemostatic treatment [16, 17]. Compared to conventional plasma-based coagulation tests like measurements of prothrombin time (PT/INR), activated partial thrombin time (aPTT) or single coagulation factor assays, ROTEM ${ }^{\circledR}$ measures the viscoelastic properties of the clot and provides information on the speed of coagulation initiation, kinetics of clot growth, clot strength and breakdown [18]. In brief summary, ROTEM ${ }^{\circledR}$ might allow for an early and more target-aimed treatment with the administration of specific hemostatic agents, blood products and coagulation factor concentrates [19, 20].

Therefore, the intention of our present study was to evaluate the impact of a ROTEM®-guided coagulation management in trauma patients on the ICU towards a daily used transfusion resuscitation and outcome in multiple traumatized patients.

\section{Patients ANd Methods}

\subsection{Inclusion Criteria}

Multiple traumatized patients [Injury Severity Score (ISS) $\geq 16$ points] aged $\geq 18$ years with primary admission to our hospital within $6 \mathrm{~h}$ after injury that were treated at our Level 1 trauma center. Patients were included between January $1^{\text {st }} 2010$ and December $31^{\text {st }} 2011$.

\subsection{Study Groups}

Between January $1^{\text {st }} 2010$ and December $31^{\text {st }}$ 2011 a total of sixty-two multiple traumatized patients were included in this study and treated prospectively according to the ROTEM®-based point-of-care method. To evaluate the impact of ROTEM ${ }^{\circledR}$ we compared this group with a comparable patients cohort $(n=109)$, who was treated according to conventional blood-/ coagulation-analyses at our hospital between January $1^{\text {st }} 2008$ and December $31^{\text {st }} 2009$. The data of these latter patients group were evaluated retrospectively.

\subsection{Demographics, Injury Severity and Injury Distribution}

Evaluated epidemiologic parameters comprised age, gender, and body mass index (BMI). Here, the admission weight and height were used to calculate the body mass index [BMI $(\mathrm{kg} / \mathrm{m} 2)]$. Injury distribution was determined on basis of the 2005 revised edition of the Abbreviated Injury Scale (AIS) and summarized to the Injury Severity Score (ISS) reflecting the overall injury severity [21]. Here, each injury is assigned an AIS score according to its relative importance on a six-point scale $(1$, minor; 2 , moderate; 3 , serious; 4, severe; 5 , critical; 6 , unsurvivable) and is allocated to one of six body regions: head and neck; face; thorax; abdomen; extremities (including pelvis); and external. Only the highest AIS score in each body region is used. The three most severely injured body regions 
have their score squared and added together to the ISS [21]. In order to detect patients with severe traumatic brain injuries we evaluated the initial Glasgow Coma Scale (GCS) [22].

\subsection{ROTEM $®$ Based Management}

Blood samples were taken from all included patients immediately after admission to the emergency room. Sample size for one testing comprised $3 \mathrm{ml}$ citrated whole blood (collected in Sarstedt ${ }^{\circledR}$ containers, Sarstedt AG\&Co, Nümbrecht, Germany). Samples then were analyzed on a regular commercially available ROTEM ${ }^{\circledR}$ delta (TEM Innovations $\mathrm{GmbH}$, Munich, Germany). Two tests were performed according to the manufacturer's instructions. EXTEM - an extrinsically activated test, and
FIBTEM - a test that is also extrinsically activated but contains Cytochalasin D to inhibit platelet function and thus, displays fibrin polymerization capability only. Coagulation management was then initiated according to the test results and the protocol displayed in figure 1. Beside classical laboratory parameters three different values of the performed tests were used in the algorithm. 1) EXTEM coagulation time (CTex) - time from coagulation initiation until beginning of clot building. 2) EXTEM maximum clot firmness (MCFex) - firmness of the developed clot at its highest degree, and 3) FIBTEM maximum clot firmness (MCFfib) firmness of the fibrin clot to evaluate maximum fibrin polymerization.

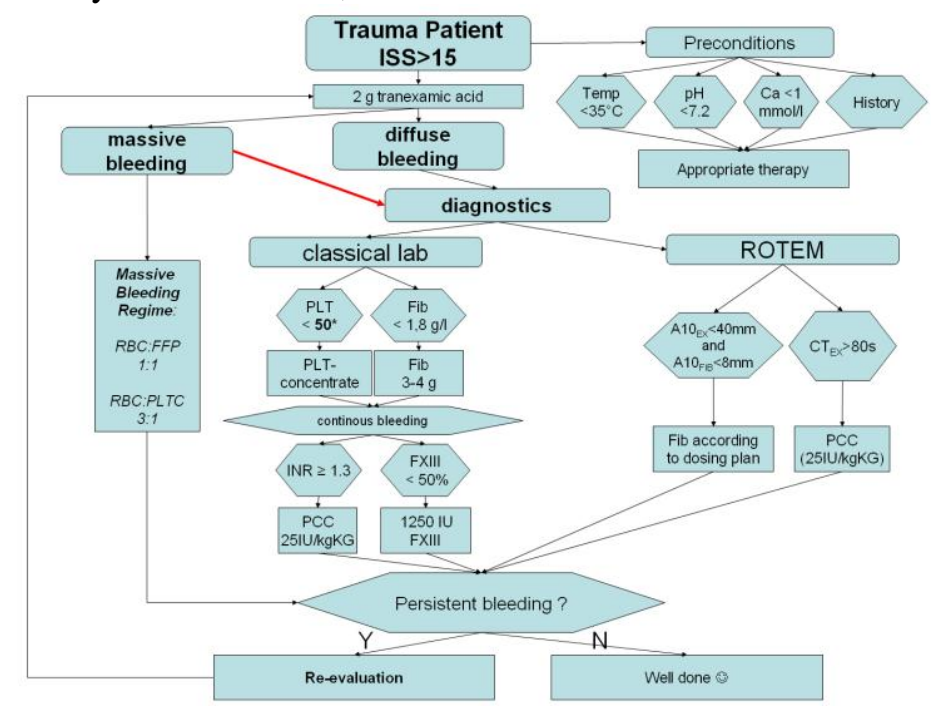

Figure1. Treatment algorithm as used in the prospective ROTEM cohort. Patients were included when showing ISS (injury severity score) of > 15 at hospital admission. Fibrinogen dosing plan is displayed in table 1. All therapeutic steps are in consensus with the European Trauma Guidelines [7].

Table1. Fibrinogen dosing plan. Fibrinogen concentrate [as displayed in gram] was administered according to A10 FIBTEM values.. Goal was a FIBTEM A 10 of $10 \mathrm{~mm}$.

\begin{tabular}{|c|c|c|c|c|c|c|c|c|c|c|}
\hline $\begin{array}{c}\text { Fibtem } \\
\text { [mm }]\end{array}$ & \multicolumn{10}{|c|}{ BODYWEIGHT [kg] } \\
\hline $\begin{array}{c}\text { A10 } \\
\text { Value }\end{array}$ & $\mathbf{5 0}$ & $\mathbf{6 0}$ & $\mathbf{7 0}$ & $\mathbf{8 0}$ & $\mathbf{9 0}$ & $\mathbf{1 0 0}$ & $\mathbf{1 1 0}$ & $\mathbf{1 2 0}$ & $\mathbf{1 3 0}$ & $\mathbf{1 4 0}$ \\
\hline $\mathbf{0}$ & 4 & 4 & 5 & 6 & 6 & 7 & 8 & 9 & 9 & 10 \\
\hline $\mathbf{1}$ & 3 & 4 & 5 & 5 & 6 & 6 & 7 & 8 & 8 & 9 \\
\hline $\mathbf{2}$ & 3 & 3 & 4 & 5 & 5 & 6 & 6 & 7 & 7 & 8 \\
\hline $\mathbf{3}$ & 3 & 3 & 4 & 4 & 5 & 5 & 6 & 6 & 7 & 7 \\
\hline $\mathbf{4}$ & 2 & 3 & 3 & 3 & 4 & 4 & 5 & 5 & 6 & 6 \\
\hline $\mathbf{5}$ & 2 & 2 & 3 & 3 & 3 & 4 & 4 & 4 & 5 & 5 \\
\hline $\mathbf{6}$ & 1 & 2 & 2 & 2 & 3 & 3 & 3 & 3 & 4 & 4 \\
\hline $\mathbf{7}$ & 1 & 1 & 2 & 2 & 2 & 2 & 2 & 3 & 3 & 3 \\
\hline $\mathbf{8}$ & 1 & 1 & 1 & 1 & 1 & 1 & 2 & 2 & 2 & 2 \\
\hline $\mathbf{9}$ & 0 & 0 & 1 & 1 & 1 & 1 & 1 & 1 & 1 & 1 \\
\hline
\end{tabular}

Furthermore, all these tests were repeatedly performed on a daily basis and the resulting coagulation treatment on the intensive care unit
(ICU) was kept equally to the algorithm used before. All patients were observed over a period of ten days following admission.

Dosing of all drugs was calculated according to the algorithm, but fibrinogen was administered according to the dosing plan displayed in table 1.

\subsection{In-Hospital Complications and Outcome}

MODS was defined according to Marshall et al. [23]. As previously described manifest MODS was considered if the score was greater than 12 points on two consecutive days or at least three days during a 14-day observation period [23, 24].

The presence of an ARDS was assumed according the recommendations of the "The American-European Consensus Conference on ARDS" [25, 26]. The primary outcome 
parameter was defined as mortality during the observational period.

\subsection{Hemostatic Management}

In order to determine the quantity of transfused blood products [packed red blood cells (pRBCs), fresh frozen plasma (FFPs), and platelets (PLTs)] all these products administered during the first ten days of ICU treatment were documented. More and above, the application of fibrinogen $\left(\mathrm{Fb}\right.$ - Haemocompletan ${ }^{\circledR}$, CSL Behring, Hattersheim, Germany), prothrombin complex concentrates (PCC - Beriplex ${ }^{\circledR}, \mathrm{CSL}$ Behring, Hattersheim, Germany) antithrombinIII (AT-III - Kybernin®, CSL Behring, Hattersheim, Germany) and tranexamic acid (TXA - Cyclokapron®, Pfizer Pharma GmbH, Berlin, Germany) was captured and the results of all clinical examinations and blood chemistry analyses were recorded.

\subsection{Ethics}

This study was exclusively performed at Hannover Medical School, Hannover, Germany. It was conducted according the guidelines of the revised UN declaration of Helsinki in 1975 and its latest amendment in 2005 and has been approved by the local Ethics Committee.

\subsection{Statistics}

All data were analyzed using the Statistical Package for the Social Sciences (SPSS; version 22; IBM Inc., Somers, NY, USA). Incidences are presented with counts and percentages while continuous values are presented as mean \pm standard deviation (SD). Differences between groups were evaluated by the univariate analysis of variances (ANOVA) for continuous data, while Pearson's $\chi 2$-test was used for categorical values. In order to reveal the impact of ROTEM ${ }^{\circledR}$ on outcome, a multivariate logistic regression analysis was performed with mortality as a target variable and age, gender, BMI, injury severity (ISS), initial GCS, pRBCs, FFPs, PLTs, Fb, PPSB, AT-III, and TXA as potential predictors. Odds ratios with 95\% confidence intervals $(95 \%$-CI) were noted. A two-sided p-value $<0.05$ was considered to be significant.

\section{Results}

According to the study protocol a total of 171 adult multiple traumatized patients were included in this study. Out of these 62 patients were treated according to the point-of-care
ROTEM ${ }^{\circledR}$ management and thus, were evaluated prospectively, while 109 patients represented the retrospective cohort and were managed on basis of conventional blood analyses. The average age of all patients was $43.6 \pm 19.9$ years. Gender distribution revealed $72.5 \%(\mathrm{n}=124)$ male patients. Overall mortality was $18.7 \%(\mathrm{n}=32)$.

\subsection{Demographics, Injury Severity and Transfusion Management}

Statistical analyses regarding age, BMI, ISS, and initial GCS revealed no significant differences between study groups (table 2). However, patients treated according to ROTEM ${ }^{\circledR}$ received less frequently pRBCs, FFPs, and PLTs during the observational period whereas the overall amount of administered blood products was comparable (table 2). Furthermore, the administration of TXA and $\mathrm{Fb}$ was increased compared to the retrospectively evaluated study group while PPSB and AT-III did not differ between groups (table 3 )

Table2. Demographics, injury severity scores and transfusion requirement of both groups (ROTEM vs. retrospective cohort). Abbreviations are: BMI - body mass index; GCS - Glascow coma scale; AIS abbreviated injury score; ISS - injury severity score; pRBC - pooled red blood cell concentrate; ICU intensive care unit; FFP - fresh frozen plasma; PLT - platelet concentrate. A p-value below 0.05 can be considered as significant.

\begin{tabular}{|c|c|c|c|}
\hline & ROTEM $\AA$ & $\begin{array}{c}\text { Retrospective } \\
\text { Cohort }\end{array}$ & p-value \\
\hline Age (years) & $\begin{array}{c}44,0 \pm \\
17,5\end{array}$ & $43,3 \pm 21,1$ & 0,837 \\
\hline BMI & $26,6 \pm 5,1$ & $25,0 \pm 4,6$ & 0,056 \\
\hline $\begin{array}{c}\text { Gender } \\
\text { (male) }\end{array}$ & $\begin{array}{c}50 \\
(80.6 \%)\end{array}$ & $74(67.9 \%)$ & 0.072 \\
\hline Initiale GCS & $10,5 \pm 4,7$ & $9,5 \pm 5,1$ & 0,224 \\
\hline AIS head & $1.8 \pm 1.8$ & $2.6 \pm 1.9$ & 0.016 \\
\hline AIS face & $0.7 \pm 1.2$ & $0.8 \pm 1.1$ & 0.489 \\
\hline AIS chest & $3.1 \pm 1.3$ & $2.9 \pm 1.7$ & 0.483 \\
\hline $\begin{array}{c}\text { AIS } \\
\text { abdomen }\end{array}$ & $1.4 \pm 1.9$ & $1.1 \pm 1.6$ & 0.280 \\
\hline $\begin{array}{c}\text { AIS } \\
\text { extremities }\end{array}$ & $2.2 \pm 1.7$ & $1.9 \pm 1.4$ & 0.283 \\
\hline ISS & $33,3 \pm 11,2$ & $31,0 \pm 11,8$ & 0,220 \\
\hline pRBCs ICU & $1,9 \pm 4.6$ & $9.8 \pm 9.3$ & $<0.001$ \\
\hline FFPs ICU & $1,0 \pm 4.5$ & $12.7 \pm 13.1$ & $<0.001$ \\
\hline PLTs ICU & $0.1 \pm 0.4$ & $5.4 \pm 7.6$ & $<0.001$ \\
\hline
\end{tabular}

\subsection{Clinical Course and Outcome}

Regarding the clinical course and -outcome, patients treated by ROTEM ${ }^{\circledR}$ developed less 
frequently ARDS, while the incidence of MODS and mortality was comparable between study groups (table 3).

Table3. Hemostatic management and clinical outcome of both groups. Abbreviations are: PCC prothrombin complex concentrate; TXA - tranexamic acid; ATIII - antithrombin III concentrate; MODS multiorgan dysfunction syndrome; ARDS - acute respiratory distress syndrome. A p-value below 0.05 can be considered as significant.

\begin{tabular}{|c|c|c|c|}
\hline & ROTEM $®$ & $\begin{array}{c}\text { Retrospective } \\
\text { Cohort }\end{array}$ & p-value \\
\hline Fibrinogen & $2,6 \pm 2.6$ & $1,0 \pm 2.2$ & $<0,001$ \\
\hline PCC & $\begin{array}{c}1,391.7 \pm \\
2113.5\end{array}$ & $\begin{array}{c}1,039.0 \pm \\
2707.8\end{array}$ & 0,384 \\
\hline TXA & $1.0 \pm 1.2$ & $0.0 \pm 0.0$ & $<0,001$ \\
\hline AT-III & $279.7 \pm$ & $422.0 \pm 1539.9$ & 0,512 \\
& 847.3 & & 0,504 \\
\hline MODS & $2(3,5 \%)$ & $2(1,8 \%)$ & $<0,001$ \\
\hline ARDS & $11(19,3 \%)$ & $51(47,2 \%)$ & $<13$ \\
\hline Mortality & $10(16.1 \%)$ & $22(20.2 \%)$ & 0.513 \\
\hline
\end{tabular}

\subsection{Potential Impact of ROTEM $®$ Towards Outcome}

According to a stepwise logistic regression analysis the application of TXA was identified to be the most important predictor of survival (OR $0.446, \mathrm{p}=0.041$ ) followed by application of $\mathrm{Fb}$ (OR 0.915, p=0.021) (table 4). Age, injury severity, and the administration of platelets were found as potential predictors towards mortality whereas all other included potential predictors could be excluded during the stepwise regression analysis.

Table4. Data refer to mortality analyzing age, gender, body mass index (BMI), injury severity (ISS), initial Glascow coma scale (GCS), packed red blood cell (pRBCs), fresh frozen plasma (FFPs), platelet concentrates (PLTS), fibrinogen concentrate $(F b)$, prothrombin complex concentrates (PCC), antithrombin III (AT-III), and tranexamic acid (TXA) as potential predictors

\begin{tabular}{|c|c|c|c|c|}
\hline Predictor & $\begin{array}{l}\text { Regression } \\
\text { coefficient }\end{array}$ & $\begin{array}{l}\text { Odds } \\
\text { Ratio }\end{array}$ & $95 \%$-CI & $\begin{array}{c}\text { p- } \\
\text { value }\end{array}$ \\
\hline Age & 0.054 & 1.055 & $\begin{array}{l}1.025- \\
1.086\end{array}$ & $<0.001$ \\
\hline ISS & 0.124 & 1.132 & $\begin{array}{c}1.074- \\
1.194\end{array}$ & $<0.001$ \\
\hline $\mathbf{F b}$ & -0.089 & 0.915 & $\begin{array}{c}0.849- \\
0.986 \\
\end{array}$ & 0.021 \\
\hline PLTs & 0.318 & 1.374 & $\begin{array}{c}1.015- \\
1.859\end{array}$ & 0.040 \\
\hline PCC & 0.000 & 1.000 & $\begin{array}{l}1.000- \\
1.000\end{array}$ & 0.074 \\
\hline TXA & -0.807 & 0.446 & $\begin{array}{c}0.206- \\
0.969\end{array}$ & 0.041 \\
\hline \begin{tabular}{|l|} 
constant \\
\end{tabular} & -8.360 & - & - & $<0.001$ \\
\hline
\end{tabular}

\section{DISCUSSION}

In 1948 Hartert developed a viscoelastic test method to analyse blood clots as a final product of the coagulation cascade [27]. Today, this original technique is still used in form of thrombelastography devices (TEG®, Haemonatics, Braintree, MA, USA). The ROTEM ${ }^{\circledR}$ technique applied in our present study also bases on Hartert's test method but uses activated tests and a more robust setting [28]. Here, in contrast to regular laboratory coagulation tests ROTEM ${ }^{\circledR}$ provides more precious information on the clot itself and its formation dynamics.

The efficacy of ROTEM® based coagulation treatment in different clinical settings has been shown in several recently published manuscripts already. However, while in other clinical settings, e.g. cardiac surgical patients some prospective trials on the use of point-of-care devices such as ROTEM ${ }^{\circledR}$ for the coagulation management have been published [29, 30], studies in the special setting of trauma patients are exclusively of retrospective nature $[18,20$, $31,32]$. Thus, prospective data on these patients are still missing. One reason might be the fact that the treatment of trauma patients can not be scheduled and patients, trauma patterns, and physician teams may profoundly differ leading to inhomogeneous patient/study groups and difficulties in performing prospective trials under standardized conditions. Therefore, we decided for an at least partial prospective study design, performed exclusively on our ICU. Here it was possible to use well defined infrastructural conditions, i.e. a well educated staff and standardized treatment algorithms directly after changing and establishing the general coagulation management for all trauma patients towards point of care-based methods.

It has been shown retrospectively that the introduction of near patient methods for coagulation testing and goal directed management may lead to a reduction of the transfusion of allogenic blood products [20]. In our present study we could approve these findings for that the prospectively analysed patient group necessitated significantly less blood products. Furthermore we notified a significant reduction in the development of ARDS, which may be causally linked to a reduced transfusion of fresh frozen plasma in these patients. This is an interesting and at least potentially essential observation for that the 
transfusion of FFP has also been shown to be responsible for the development of TRALI [3335]. More and above, the reduction of FFP administration itself may also be responsible for the reduction of $\mathrm{pRBC}$ transfusion as observed in our present study and has also been shown in a prospective cohort study by Innerhofer and coworkers [36]. Mechanistically they claimed that a reduced dilution of haemoglobin by FFP may be responsible for the reduction of transfusion necessity.

Interestingly, the ROTEM ${ }^{\circledR}$ managed group necessitated significantly more TXA and $\mathrm{Fb}$ than the conventional managed control group. However, this is in line with data identified in the CRASH2 study which reported on a major survival benefit of the early use of TXA and which in turn is regarded as standard since then. And indeed, we were also able to identify the application of TXA as an independent predictor for survival. More and above, $\mathrm{Fb}$ also revealed significant benefit and thus, seem to represent a second essential predictor for survival. The efficacy of the application of coagulation factor concentrates according to a similar algorithm to that used in our current study has also been described in a retrospective study conducted by Schöchl and coworkers [18]. However, they compared the efficacy of coagulation factor concentrate application to predictive score models (trauma injury severity score (TRISS) and the revised injury severity classification (RISC)).

Our data support these earlier findings in terms of $\mathrm{Fb}$ application.

\section{Limitations}

In our present study we evaluated prospectively collected data of severely traumatized patients and compared these data to a retrospective patient group who was treated before changing our coagulation management towards an early goal directed and ROTEM ${ }^{\circledR}$ based treatment. Thus, the resulting evidence of our data is not as accurate as such provided by a prospective and randomized trial. However, until now and due to the above mentioned reasons those trials are not and probably will not be available for trauma patients in the near future so that our approach may still represent the most accurate way possible in this patients group. It lays in the nature of trauma patients that they never arrive foreseeable in the emergency room but based on our study design it may be possible to further elevate data accuracy by transferring and applying our study design to a multicenter study cohort in the near future.

\section{Conclusions}

ROTEM®-guided hemostatic management led to a reduced transfusion of blood products in multiple traumatized patients and resulted in a highly significant decrease of ARDS. More and above, the calculated administration of TXA according to the used algorithm seems to have strong impact on the incidence of mortality. Thus, although additional studies are mandatory to further elucidate the clinical value in the daily routine, our current results strongly indicate a decisive diagnostic and hence outcome impact of the method.

\section{ACKNOWLEDGEMENT}

We would like Brigitte Buchalik for excellent laboratory support.

\section{CONFLICTS OF INTERESTS}

Michaela Wilhelmi received honoraria and travel support for educational lectures from CLS Behring, Hattersheim, Germany. Alexander A. Hanke received honoraria and travel support for educational lectures from CLS Behring, Hattersheim, Germany, Roche Diagnostics, Mannheim, Germany, and TEM International, Munich, Germany.

\section{ETHical Statement}

Each author certifies that his or her institution approved the human protocol for this investigation, that all investigations were conducted in conformity with ethical principles of research.

\section{REFERENCES}

[1] Wafaisade A, Wutzler S, Lefering R, Tjardes T, Banerjee M, Paffrath T, Bouillon B, Maegele M: Drivers of acute coagulopathy after severe trauma: a multivariate analysis of 1987 patients. Emerg Med J 2010, 27:934-9.

[2] Sauaia A, Moore FA, Moore EE, Moser KS, Brennan R, Read RA, Pons PT: Epidemiology of trauma deaths: a reassessment. J Trauma 1995, 38:185-93.

[3] Brohi K, Cohen MJ, Davenport R a: Acute coagulopathy of trauma: mechanism, identification and effect. Curr Opin Crit Care 2007, 13:680-5.

[4] Hess JR, Brohi K, Dutton RP, Hauser CJ, Holcomb JB, Kluger Y, Mackway-Jones K, Parr MJ, Rizoli SB, Yukioka T, Hoyt DB, 
Bouillon B: The coagulopathy of trauma: a review of mechanisms. J Trauma 2008, 65:748-54.

[5] Esmon CT: The interactions between inflammation and coagulation. Br J Haematol 2005, 131:417-30.

[6] Kauvar DS, Lefering R, Wade CE: Impact of hemorrhage on trauma outcome: an overview of epidemiology, clinical presentations, and therapeutic considerations. J Trauma 2006, 60(6 Suppl):S3-11.

[7] Rossaint R, Bouillon B, Cerny V, Coats TJ, Duranteau J, Fernández-Mondéjar E, Hunt BJ, Komadina R, Nardi G, Neugebauer E, Ozier Y, Riddez L, Schultz A, Stahel PF, Vincent J-L, Spahn DR: Management of bleeding following major trauma: an updated European guideline. Crit Care 2010, 14:R52.

[8] Rossaint R, Cerny V, Coats TJ, Duranteau J, Fernández-Mondéjar E, Gordini G, Stahel PF, Hunt BJ, Neugebauer E, Spahn DR: Key issues in advanced bleeding care in trauma. Shock 2006, 26:322-31.

[9] Maegele M, Lefering R, Paffrath T, Tjardes T, Simanski C, Bouillon B: Red-blood-cell to plasma ratios transfused during massive transfusion are associated with mortality in severe multiple injury: a retrospective analysis from the Trauma Registry of the Deutsche Gesellschaft für Unfallchirurgie. Vox Sang 2008, 95:112-9.

[10] Sperry JL, Ochoa JB, Gunn SR, Alarcon LH, Minei JP, Cuschieri J, Rosengart MR, Maier R V, Billiar TR, Peitzman AB, Moore EE: An FFP:PRBC transfusion ratio $>/=1: 1.5$ is associated with a lower risk of mortality after massive transfusion. J Trauma 2008, 65:98693.

[11] Khan H, Belsher J, Yilmaz M, Afessa B, Winters JL, Moore SB, Hubmayr RD, Gajic O: Fresh-frozen plasma and platelet transfusions are associated with development of acute lung injury in critically ill medical patients. Chest 2007, 131:1308-14.

[12] Win N, Massey E, Lucas G, Sage D, Brown C, Green A, Contreras M, Navarrete C: Ninety-six suspected transfusion related acute lung injury cases: investigation findings and clinical outcome. Hematology 2007, 12:461-9.

[13] Gajic O, Gropper MA, Hubmayr RD: Pulmonary edema after transfusion: how to differentiate transfusion-associated circulatory overload from transfusion-related acute lung injury. Crit Care Med 2006, 34(5 Suppl):S10913.

[14] Dara SI, Rana R, Afessa B, Moore SB, Gajic O: Fresh frozen plasma transfusion in critically ill medical patients with coagulopathy. Crit Care Med 2005, 33:2667-71.

[15] Sarani B, Dunkman WJ, Dean L, Sonnad S, Rohrbach JI, Gracias VH: Transfusion of fresh frozen plasma in critically ill surgical patients is associated with an increased risk of infection. Crit Care Med 2008, 36:1114-8.

[16] Luddington RJ: Thrombelasto graphy/ thrombo elastometry. Clin Lab Haematol 2005, 27:8190.

[17] Ganter MT, Hofer CK: Coagulation monitoring: current techniques and clinical use of viscoelastic point-of-care coagulation devices. Anesth Analg 2008, 106:1366-75.

[18] Schöchl H, Nienaber U, Hofer G, Voelckel W, Jambor C, Scharbert G, Kozek-Langenecker S, Solomon C: Goal-directed coagulation management of major trauma patients using thromboelastometry (ROTEM) -guided admini stration of fibrinogen concentrate and prothrombin complex concentrate. Crit Care 2010, 14:R55.

[19] Pezold M, Moore EE, Wohlauer M, Sauaia A, Gonzalez E, Banerjee A, Silliman CC: Viscoelastic clot strength predicts coagulationrelated mortality within 15 minutes. Surgery 2012, 151:48-54.

[20] Schöchl H, Nienaber U, Maegele M, Hochleitner G, Primavesi F, Steitz B, Arndt C, Hanke A, Voelckel W, Solomon C: Transfusion in trauma: thromboelastometry-guided coagulation factor concentrate-based therapy versus standard fresh frozen plasma-based therapy. Crit Care 2011, 15:R83.

[21] Baker SP, O’Neill B, Haddon W, Long WB: The injury severity score: a method for describing patients with multiple injuries and evaluating emergency care. J Trauma 1974, 14:187-96.

[22] Teasdale G, Jennett B: Assessment of coma and impaired consciousness. A practical scale. Lancet 1974, 2:81-4.

[23] Marshall JC, Cook DJ, Christou N V, Bernard GR, Sprung CL, Sibbald WJ: Multiple organ dysfunction score: a reliable descriptor of a complex clinical outcome. Crit Care Med 1995, 23:1638-52.

[24] Frink M, Pape H-C, van Griensven M, Krettek C, Chaudry IH, Hildebrand F: Influence of sex and age on mods and cytokines after multiple injuries. Shock 2007, 27:151-6.

[25] Bernard GR, Artigas A, Brigham KL, Carlet J, Falke K, Hudson L, Lamy M, LeGall JR, Morris A, Spragg R: Report of the AmericanEuropean consensus conference on ARDS: definitions, mechanisms, relevant outcomes and clinical trial coordination. The Consensus 
Committee. Intensive Care Med 1994, 20:22532.

[26] Bernard GR, Artigas A, Brigham KL, Carlet J, Falke K, Hudson L, Lamy M, Legall JR, Morris A, Spragg R: The American-European Consensus Conference on ARDS. Definitions, mechanisms, relevant outcomes, and clinical trial coordination. Am J Respir Crit Care Med 1994, 149(3 Pt 1):818-24.

[27] Hartert H: Blutgerinnungsstudien mit der Thrombelastographie, einem neuen Unter such ungsverfahren. Klin Wochenschr 1948:577583.

[28] Lang T, von Depka M: [Possibilities and limitations of thrombelastometry/-graphy]. Hamostaseologie 2006, 26(3 Suppl 1):S20-9.

[29] Weber CF, Görlinger K, Meininger D, Herrmann E, Bingold T, Moritz A, Cohn LH, Zacharowski K: Point-of-care testing: a prospective, randomized clinical trial of efficacy in coagulopathic cardiac surgery patients. Anesthesiology 2012, 117:531-47.

[30] Rahe-Meyer N, Solomon C, Hanke A, Schmidt DS, Knoerzer D, Hochleitner G, Sørensen B, Hagl C, Pichlmaier M: Effects of Fibrinogen Concentrate as First-line Therapy during Major Aortic Replacement Surgery: A Randomized, Placebo-controlled Trial. Anesthesiology 2013, 118:40-50.
[31] Solomon C, Traintinger S, Ziegler B, Hanke A, Rahe-Meyer N, Voelckel W, Schöchl H: Platelet function following trauma. A multiple electrode aggregometry study. Thromb Haemost 2011, 106:322-30.

[32] Schöchl H, Posch A, Hanke A, Voelckel W, Solomon C: High-dose fibrinogen concentrate for haemostatic therapy of a major trauma patient with recent clopidogrel and aspirin intake. Scand J Clin Lab Invest 2010, 70:4537.

[33] Benson AB, Austin GL, Berg M, McFann KK, Thomas S, Ramirez G, Rosen H, Silliman CC, Moss M: Transfusion-related acute lung injury in ICU patients admitted with gastrointestinal bleeding. Intensive Care Med 2010, 36:1710-7.

[34] Triulzi DJ: Transfusion-related acute lung injury: current concepts for the clinician. Anesth Analg 2009, 108:770-6.

[35] Silliman CC, McLaughlin NJD: Transfusionrelated acute lung injury. Blood Rev 2006, 20:139-59.

[36] Innerhofer $P$, Westermann I, Tauber $H$, Breitkopf R, Fries D, Kastenberger T, El Attal R, Strasak A, Mittermayr M: The exclusive use of coagulation factor concentrates enables reversal of coagulopathy and decreases transfusion rates in patients with major blunt trauma. Injury 2013, 44:209-16

Citation: Michaela Wilhelmi, Mathias Wilhelmi, Christian Krettek, Felix Flöricke, Frank Hildebrand, Hagen Andruszkow, Alexander A. Hanke. Impact of Implementation of Rotem on Allogenic Blood Transfusions in Trauma Patients Following ICU Admission before and after Study. ARC Journal of Anesthesiology. 2017;2(3):10-17. doi: dx.doi.org/10.20431/2455-9792.0203004.

Copyright: (c) 2017 Authors. This is an open-access article distributed under the terms of the Creative Commons Attribution License, which permits unrestricted use, distribution, and reproduction in any medium, provided the original author and source are credited. 